\title{
Alzheimer's disease and granulocyte density diversity
}

\author{
Petter Järemo*, Micha Milovanovic ${ }^{*}$, Caroline Buller $^{*}$, Staffan Nilsson ${ }^{\dagger}$ and Bengt Winblad ${ }^{\ddagger}$ \\ ${ }^{*}$ Department of Internal Medicine, the Vrinnevi Hospital, Norrköping, Sweden, ${ }^{\dagger}$ Department of Medical and Health Sciences, \\ Division of Community Medicine/General Practice, Linköping University, Linköping, Sweden, ${ }^{\ddagger} \mathrm{KI}$-Alzheimer's Disease \\ Research Center, Department of Neurobiology, Care Sciences and Society (NVS), Karolinska Institute, Huddinge, Sweden
}

\begin{abstract}
Background The current study investigates circulating eosinophils and neutrophils in Alzheimer's (AD) type dementia with respect to density $(\mathrm{kg} / \mathrm{L})$. The existence of $\beta$-amyloid plaques in the brain is a feature of AD. Sporadic scientific reports indicate that the disease affects circulating neutrophils. In contrast, numerous publications investigate inflammatory reactions in AD brains. Locally, the plaques evoke a substantial inflammatory response involving activated microglia and astrocytes.
\end{abstract}

Methods Subjects with probable AD $(n=39)$ were included and compared with elderly individuals $(n=22)$ lacking apparent memory problems. We sampled $10 \mathrm{~mL}$ venous blood in citrate. Granulocytes were separated according to density in linear Percoll ${ }^{\mathrm{TM}}$ gradients. Subsequently, the gradients were divided into density subfractions $(n=16)$. In every fraction, determination of eosinophil and neutrophil counts was carried out.

Results AD sufferers displayed less granulocytes in fractions nos. 13-15 containing light cells. For these fractions, the $P$-values proved to be $(P<0.001$; not significant; $P=0.03)$ and $(P=0.01 ; P=0.01$; not significant), for eosinophils and neutrophils, respectively.

Conclusions The present work describes that less circulating light granulocytes are a feature of AD demented individuals. It is to hypothesize that it is a sign of impaired granulocyte turnover and cell damage. It is concluded that $A D$ affects inflammatory cells in the periphery and that the behaviour of granulocytes in dementia is worthwhile further studies.

Keywords Alzheimer's disease, cell density, eosinophils, granulocytes, neutrophils.

Eur J Clin Invest 2013

\section{Introduction}

Outside the brain granulocytes, that is eosinophils and neutrophils are the first phagocytes to be in contact with invading bacteria. The cells then produce reactive oxygen intermediates of use in microbial killing. When activated, granulocytes also release a striking array of proteolytic enzymes. Examples include elastase and myeloperoxidase [1]. The blood-brain barrier safeguards the brain from the remainder of the body. In the brain, the immune system comprises of microglia, that is, resident brain macrophages believed to be the local representative of the monocyte-macrophage lineage [2]. Furthermore, in the cerebral cortex, astrocytes perform many functions associated with the immune response. The latter cells have phagocytic properties, and they are constituents of the blood-brain barrier.

The prevalence of Alzheimer dementia (AD) is escalating. Today, the pathogenesis of the disease eludes our comprehen-

P. Järemo and M. Milovanovic participated equally to the science. sion. Senile plaques, that is, insoluble amyloid deposits in critical regions of the cerebral cortex are hallmarks of AD. The final diagnosis is dependent on post-mortem demonstration of amyloid plaques in the brain. The toxic self-aggregating $\beta$-amyloid peptides, the key constituent of the plaques, arise through proteolysis of the ubiquitous $\beta$-amyloid precursor protein [3]. To date, no reasonable experimental data have shown a connection between amyloid plaques and the recruitment of neutrophils to the brain. However, activated microglia and astrocytes surround the amyloid plaques [4]. The latter cells are major sources of oxidizing radical species causing local cell damage [5].

AD-type dementia is associated with a substantial elevation of oxidative stress levels in circulating neutrophils [6]. The cells further contain $\beta$-amyloid peptides in their phagocytic granule [7]. Myeloperoxidase a myeloid-specific agent is found in amyloid plaques [8]. In dementia, surface expression of adhesion molecules on neutrophils is increased [9]. In the periphery, 
phagocytosis of $\beta$-amyloid- peptides is defective [10] and even in early stages of the disease, granulocyte ability to engulf microbes is impaired [11]. Together these findings leave the door open for a potential role of granulocytes in AD pathophysiology.

In early disease, it is difficult to distinguish $\mathrm{AD}$ from other conditions causing memory impairments. Easy accessible biomarkers are necessary both for diagnosis and for precise classification of dementia according to latest diagnostic criteria. Previous communications from our laboratory present an approach to separate cells according to density [12-15]. The AD disease process appears to be associated with density alterations of cells such as erythrocytes [16] and platelets [17]. The results make us suspect that $\mathrm{AD}$ is deleterious to circulating blood cells [16,17]. The intention of this work is to find features of circulating granulocytes, that is, eosinophils and neutrophils being characteristic for AD.

\section{Material and methods}

All patients and/or responsible parties gave informed consent to participate. The local ethical committee approved the study protocol. Thirty-nine AD patients (19 females) (age $70 \pm 8$ (SD) years) and 22 elderly (12 females) lacking obvious memory problems (age $66 \pm 9$ (SD) years) were investigated. Table 1 shows demographic characteristics. Experienced geriatricians set the AD diagnosis, and we did not apply specific exclusion criteria. However, as shown in Fig. 1, the demented group with a high degree of certainty contains mixed form of dementia as well. We separated granulocytes according to density $(\mathrm{kg} / \mathrm{L})$ into 16 different fractions. Previous publications describe the procedure in details [12-15]. In all fractions, determination of eosinophil and neutrophil counts was carried out electronically. We employed the chi-square test and the Student's $t$-test for statistical evaluation. Reporting of the present study conforms to current guidelines [18].

\section{Results}

Figures 1(a, b) (eosinophils) and 2(a, b) (neutrophils) give the distribution of cells in the density gradient. It is evident that AD-type dementia is associated with less low-density granulocytes. For the light fractions nos. 13-15, the $P$-values were $(P<0.001$; not significant; $P=0.03)$ and $(P=0.01 ; P=0.01$; not significant), for eosinophils and neutrophils, respectively.

\section{Discussion}

This study investigates granulocyte density alterations of circulating eosinophils and neutrophils in AD dementia sufferers. Abundant evidence indicates active inflammatory processes in AD. However, science dedicated to peripheral granulocytes in
Table 1 Demographic data for the two study groups. The Student's t-test and the chi-square test were employed for statistical evaluation

\begin{tabular}{|c|c|c|c|}
\hline & $\begin{array}{l}\text { Alzheimer's } \\
\text { disease }(n=39)\end{array}$ & $\begin{array}{l}\text { Controls } \\
(n=22)\end{array}$ & $P$-value \\
\hline Age (years) & $70 \pm 8$ & $66 \pm 9$ & 0.040 \\
\hline $\operatorname{Sex}(f / m)$ & $20 / 19$ & $10 / 12$ & NS \\
\hline Alcohol problems $(n)$ & 3 & 0 & NS \\
\hline Diabetes $(n)$ & 1 & 0 & NS \\
\hline Heart disease $(n)$ & 8 & 1 & NS \\
\hline Hypertension ( $n)$ & 16 & 14 & NS \\
\hline Aspirin $(n)$ & 4 & 3 & NS \\
\hline ACE-inhibitors $(n)$ & 3 & 6 & NS \\
\hline $\mathrm{A}_{2}$-blockers $(n)$ & 1 & 5 & NS \\
\hline$\beta$-blockers $(n)$ & 9 & 6 & NS \\
\hline $\mathrm{Ca}^{2+}$-blockers $(n)$ & 4 & 7 & NS \\
\hline Diuretics $(n)$ & 5 & 3 & NS \\
\hline Statins $(n)$ & 3 & 6 & NS \\
\hline Diabetes $(n)$ & 1 & 0 & NS \\
\hline Heart disease $(n)$ & 8 & 1 & NS \\
\hline Hypertension (n) & 16 & 14 & NS \\
\hline
\end{tabular}

Acetylcholine esterase

17

inhibitors $(n)$

Signs of brain atrophy

18

(CT) $(n)$

Signs of ischaemic brain

4

damage (CT) $(n)$

Normal brain x-ray (CT) $(n) \quad 10$

No brain x-ray (CT) (n)

6

$\mathrm{CT}$, computer tomography;

NS, not significant.

AD is sparse. To our knowledge, the behaviour of eosinophils in $\mathrm{AD}$ has not been investigated previously. In contrast, in AD-type dementia, extensive scientific work is devoted to inflammation in the central nervous system. The toxic substance $\beta$-amyloid triggers responses of microglia and astrocytes, and activated inflammatory cells are a feature of senile plaques.

Earlier publications describe the density gradient employed for separating granulocytes according to density extensively [12 -17]. For each density fraction, we determined the mean values for the $39 \mathrm{AD}$ patients and the 22 controls with respect to granulocyte numbers. Subsequently, we employed the 
(a)

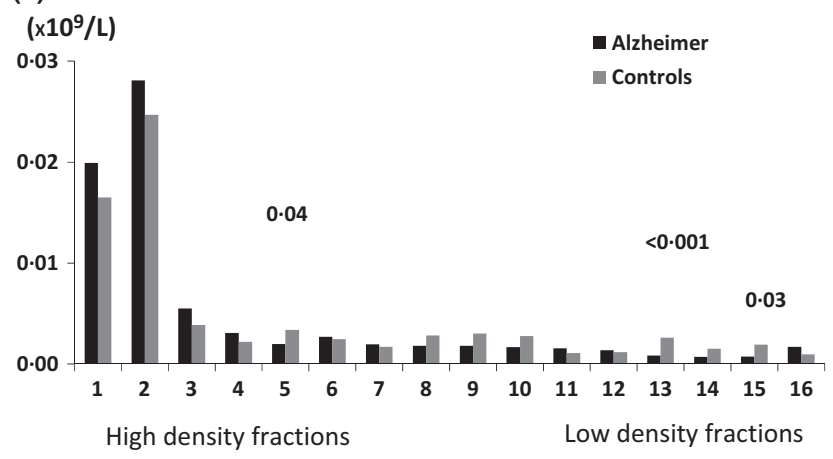

(b)

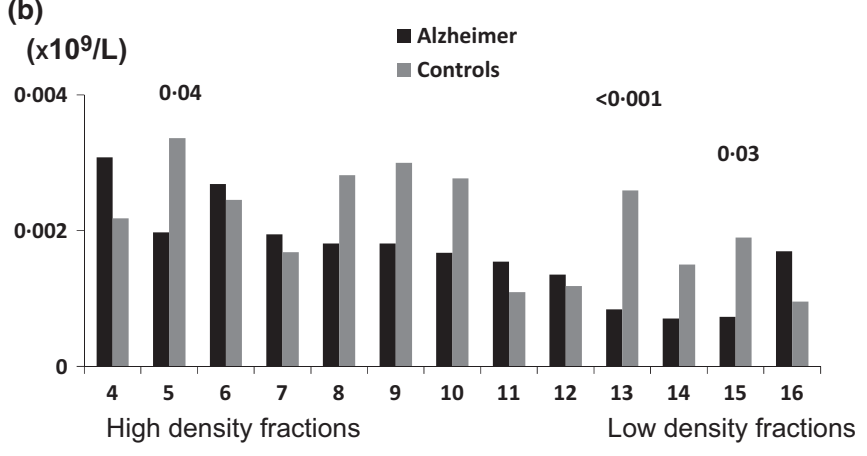

Figure 1 (a) The figure demonstrates the eosinophil distribution in the entire density gradient. Significant $P$-values are shown over the bars. (b) The figure displays the eosinophil distribution in the gradient. The three densest fractions containing most of the eosinophils are excluded. Significant $P$-values are given over the bars.

Student's t-test to calculate differences between means. It is likely that some of the significant disparities between groups are due to chance alone. However, with respect to light granulocyte populations, both cell lines demonstrate multiple significant differences close to each other. It is, thus, to assume that $\mathrm{AD}$ is associated with a decreased number of light granulocytes (Figs 1 and 2).

In health, activated platelet populations circulate degranulated [15]. It is to hypothesize that granulocytes activate in the circulation as well. They then lose granule and density subse-quently declines. It is to theorize that $\mathrm{AD}$ diminishes this putative mechanism and that the current results are indicative of impaired granulocyte turnover. It may be a sign of less cell functionality in AD-type dementia. The data encourage future research with respect to circulating granulocytes in AD.

\section{Acknowledgements}

The authors appreciate financial support from the Ahlen's Foundation and the Gun and Bertil Stohne's Foundation. The (a)

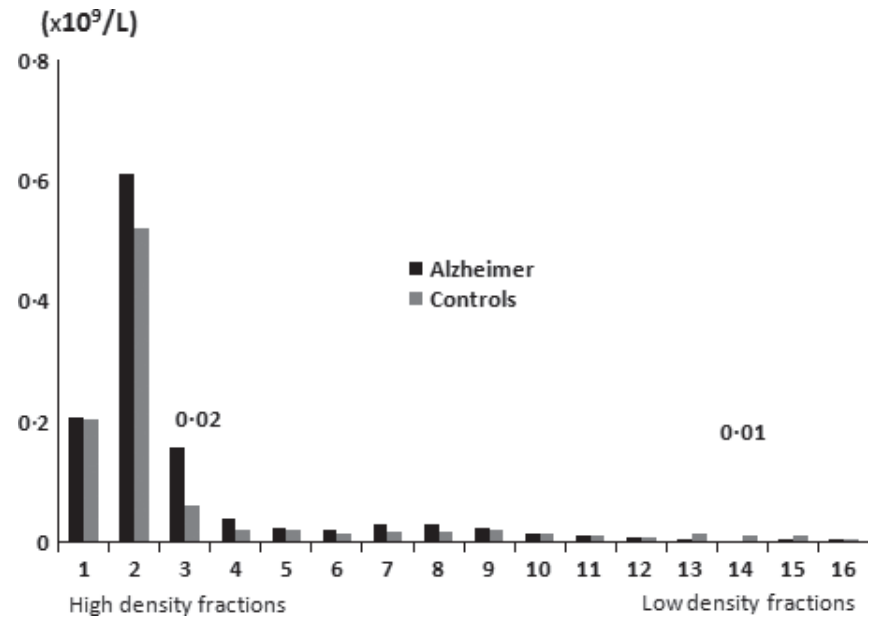

(b)

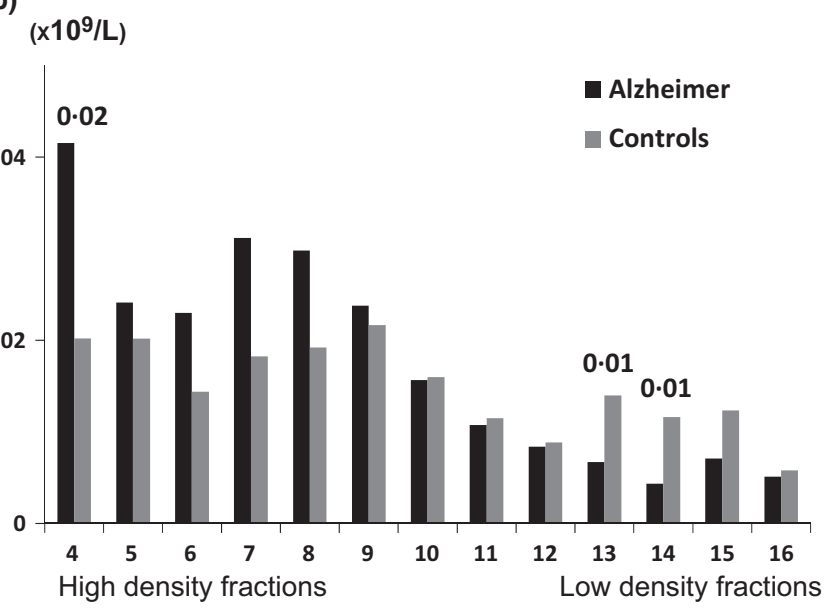

Figure 2 (a) The figure shows the density distribution of neutrophils in the entire gradient. Significant $P$-values are shown over the bars. (b) The figure shows the neutrophil distribution in the gradient. The three densest fractions containing most of the neutrophils are excluded. Significant $P$-values are given over the bars.

Magn. Bergvall's Foundation, the 'Stiftelsen för Gamla Tjänarin-nor' and the Swedish Alzheimer Foundation contributed to the research. We acknowledge grants from the Swedish Board for Health and Welfare and Pfizer AB. Finally, substantial financial support from the Hultman's Foundation for Science made this study possible.

Correspondence to: Petter Järemo, Department of Internal Medicine, The Vrinnevi Hospital, S-601 82 Norrköping, Sweden. Tel./fax: +4611125662; e-mail: petter.jaremo@telia.com

Received 27 August 2011; accepted 23 February 2013 


\section{References}

1 Järemo P, Shaba A, Kutti J. Some storage characteristics of buffy coats used for the preparation of platelet concentrates. Ann Hematol 1992;65:269-73.

2 Auffray C, Sieweke MH, Geissmann F. Blood monocytes: development, heterogeneity, and relationship with dendritic cells. Annu Rev Immunol 2009;27:669-92.

3 Kokjohn TA, Van Vickle GD, Maarouf CL, Kalback WM, Hunter JM, Daugs ID et al. Chemical characterization of pro-inflammatory amyloid-beta peptides in human atherosclerotic lesions and platelets. Biochim Biophys Acta 2011;1812:1508-14.

4 Dickson DW. The pathogenesis of senile plaques. J Neuropath Exp Neurol 1997;56:321-39.

5 Colton CA, Gilbert DL. Microglia, an in vivo source of reactive oxygen species in the brain. Adv Neurol 1993;59:321-6.

6 Vitte J, Michel BF, Bongrand P, Gastaut JL. Oxidative stress level in circulating neutrophils is linked to neurodegenerative diseases. J Clin Immunol 2004;24:683-92.

7 Nordstedt C, Näslund J, Thyberg J, Messamore E, Gandy SE, Terenius L. Human neutrophil phagocytic granules contain a truncated soluble form of the Alzheimer beta/A4 amyloid precursor protein (APP). Biol Chem 1994;269:9805-10.

8 Reynolds WF, Rhees J, Maciejewski D, Paladino T, Sieburg H, Maki RA, Masliah E. Myeloperoxidase polymorphism is associated with gender specific risk for Alzheimer's disease. Exp Neurol 1999;155:3141.

9 Scali C, Prosperi C, Bracco L, Piccini C, Baronti R, Ginestroni A et al. Neutrophils CD11b and fibroblasts PGE(2) are elevated in Alzheimer's disease. Neurobiol Aging 2002;23:523-30.
10 Fiala M, Lin J, Ringman J, Kermani-Arab V, Tsao G, Patel A et al. Ineffective phagocyte-sis of amyloid-beta by macrophages of Alzheimer's disease patients. J Alzheimers Dis 2005;7:221-32.

11 Davydova TV, Fomina VG, Voskresenskaya NI, Doronina OA. Phagocytic activity and state of bactericidal systems in polymorphonuclear leukocytes from patients with Alzheimer's disease. Bull Exp Biol Med 2003;136:355-7.

12 Järemo P. Computerised method for recording platelet density distribution. Eur J Haematol 1995;54:304-9.

13 Järemo P, Sandberg-Gertzen H. Platelet density and size in inflammatory bowel disease. Thromb Haemost 1996;75:560-1.

14 Milovanovic M, Lysen J, Ramström S, Lindahl TL, Richter A, Järemo P. Identification of low-density platelet populations with increased reactivity and elevated alpha-granule content. Thromb Res 2003;111:75-80.

15 Milovanovic M, Lotfi K, Lindahl TL, Hallert C, Järemo P. Platelet density subpoplations in essential thrombocythemia and healthy volunteers. Pathophysiol Haemost Thromb 2010;37:35-42.

16 Järemo P, Milovanovic M, Nilsson S, Buller C, Post C, Winblad B. Alzheimer's disease is characterized by more low density erythrocytes with increased volume and enhanced $\beta$-amyloid X-40 content. J Int Med 2011;270:489-92.

17 Järemo P, Milovanovic M, Nilsson S, Buller C, Winblad B. Platelet heterogeneity and Alzheimer's disease: low density platelets populations demonstrate low in vivo activity. Platelets 2012;23:11620.

18 Simera I, Moher D, Hoey J, Schulz KF, Altman DG. A catalogue of reporting guidelines for health research. Eur J Clin Invest 2010;40: 35-53. 